\section{Obstetric liaison}

SIR: The article by Appleby et al (Journal, April 1989, 154, 510-515) was interesting to all those attempting to provide a liaison service in a general hospital with an obstetric unit. However, I was concerned that they had not received any referrals for women who had experienced miscarriages or stillbirths.

Recently I have seen two cases of women presenting as parasuicides less than a week after a miscarriage. At the time of their miscarriage they were not given any supportive counselling by nursing or medical staff, and they were expected to "carry on as normal' after the event. This they were clearly unable to do.

I think it would be worthwhile providing training for medical staff and midwives so that they may be able to help these women in order to alleviate further psychiatric difficulties.

Walsgrave Hospital

GABRIELle MiLNER

Clifford Bridge Road

Walsgrave

Coventry CV2 2DX

\section{Calcium techniques}

SiR: Patel et al (Journal, December 1988, 154, 849) point out additional factors for consideration in further studies of the relationship between calcium and extrapyramidal symptoms. They do not mention desirable scientific requirements of calcium assays, nor indicate whether their own collection and assay techniques involved standardisation or correction.

Firstly, the length of venostasis has a critical effect on measured serum calcium levels, for which omission of a tourniquet achieves consistency (Zilva \& Pannall, 1981). Secondly, it is well recognised that ionised calcium $\left(\mathrm{Ca}^{2+}\right)$, rather than the total serum calcium, represents the biologically active fraction. While albumin-adjusted calcium (or corrected calcium) corresponds closely to $\mathrm{Ca}^{2+}$ (Larrson \& Ohman, 1978), technology now permits the direct measurement of ionised calcium (Bowers et al, 1986).

Consideration of these factors should strengthen the interpretation of further research in this area.

All Birmingham Rotational Training Scheme MARCELlino G. SMYTH Charles Brown Clinic Queensbridge Road Moseley

Birmingham B13 8QD

\section{References}

Bowers, G. N. Jr, Brassard, C. \& Sena, F. (1986) The measurement of ionized calcium in serum with ion-selective electrodes: a mature technology that can meet the daily service needs. Clinical Chemistry, 32, 1427-1443.

Larrson, L. \& Ohman, S. (1978) Serum ionized calcium and corrected total calcium in borderline hyperparathyroidism. Clinical Chemistry, 24, 1962-1965.

Zilva, J. \& Pannall, P. (1981) Clinical Chemistry in Diagnosis and Treatment, pp 455-456. London: Lloyd-Luke (Medical Books).

\section{Neuroleptic malignant syndrome}

SIR: Goldwasser et al (Journal, January 1989, 154, 102-104) discuss the major difficulty of how to manage acute psychiatric disturbance in those concomitantly suffering from neuroleptic malignant syndrome (NMS). Their contribution to this subject is timely. However, I would like to make two points.

They state that they believe that their two cases are the first reported where definite NMS existed and terminated while the patient was still being treated with antipsychotic drugs. I reported a case in the Journal (McCarthy et al, 1988) of a similar occurrence, and these new cases represent interesting support for our conclusions in that paper.

Dr Goldwasser et al also discuss the value of creatinine phosphokinase measurements (CPK) in these patients. Although of definite value, there are limitations to the usefulness of these measurements. It is important to note that CPK may not be elevated at all in some cases of definite NMS (Levenson, 1985), or may only be elevated at a late stage of the illness. An elevation of CPK can also occur for many other reasons, e.g. after intramuscular injections. A measurement of CPK should therefore be only one of the criteria for the diagnosis and management of NMS.

Department of Psychiatry

ANTHONY MCCARTHY

Guy's Hospital

St Thomas Street

London SE1 9RT

\section{References}

LeVEnson, J. L. (1985) Neuroleptic malignant syndrome. American Journal of Psychiatry, 142, $1137-1145$.

MCCARThy, A., BOURKE, S., FAHY, J., el al (1988) Fatal recurrence of neuroleptic malignant syndrome. British Journal of Psychiatry. 152, 558-559.

\section{NMS and thioxanthenes}

SIR: I am a little perplexed by the claim of Kemperman (Journal, April 1989, 154, 562-563) that the equal D1 and D2 receptor binding characteristics of the thioxanthenes may be responsible for the low 